\title{
The Gut-Brain Axis
}

\author{
Nobutaka Hattori ${ }^{\mathrm{a}}$ Yuichiro Yamashiro ${ }^{\mathrm{b}}$ \\ ${ }^{a}$ Department of Neurology, Juntendo University School of Medicine, Tokyo, Japan; ${ }^{b}$ Probiotics Research Laboratory, \\ Juntendo University Graduate School of Medicine, Tokyo, Japan
}

The concept of the gut-brain axis (GBA) has existed for more than 3 decades [1]. Gastrointestinal motor and sensory components send messages to the central nervous system (CNS), and the return response to the intestine is the definition of the GBA [2]. Nutrition affects microbiota colonization and gut metabolites, which can influence brain development and function through neural, immunological, and endocrine pathways [3]. The brain is the central component of the GBA and includes connections between the cerebral cortex, the limbic system, the hypothalamic-pituitary axis, and the brain system. The limbic system receives input from other brain regions including the hippocampus, which is responsible for a range of behaviors [4]. The peripheral components of the GBA communicate with the CNS through the enteric, autonomic, and sympathetic nervous systems $[5,6]$. The enteric nervous system, which resides within the intestinal wall, communicates with the brain via the vagus nerve, dorsal root, and nodose ganglia [5]. The hypothalamicpituitary axis, the autonomic nervous system, and the sympathetic nervous system are integrated peripheral components of the GBA [7]. The afferent vagus nerve is a major retrograde signaling system from the gut to the brain [8]. The efferent vagus nerve-based cholinergic anti-inflammatory pathway regulates the balance between

karger@karger.com www.karger.com/anm Karger"
(C) 2021 The Author(s)

Published by S. Karger AG, Basel

This is an Open Access article licensed under the Creative Commons Attribution-NonCommercial-4.0 International License (CC BY-NC) (http://www.karger.com/Services/OpenAccessLicense), applicable to the online version of the article only. Usage and distribution for commercial purposes requires written permission. tumor necrosis factor- $\alpha$ and other cytokines secreted by macrophages in response to stress signals in the gut [9]. This inflammation can result in the loss of intestinal epithelial barrier function, which allows bacterial invasion. Bacterial invasion leads to an increase in intestinal permeability and activation of immune and somatic cells through pathogen-associated molecular patterns including lipopolysaccharides (LPS, endotoxin), which are recognition receptors that trigger inflammation in the gut [6]. Signals sent through the systemic and intestinal immune system via the GBA cause alterations in brain function and disease. During a state of stress, hormone and neuropeptide secretion in the gut ultimately invokes cortisol release from the adrenal gland via signals though the hypothalamus. The GBA influences intestinal immune cells via norepinephrine and neuropeptide messengers, such as vasoactive intestinal peptide, and these modulate the function of dendritic cells and T cells located throughout the wall of the intestine and in secondary lymphoid tissues, such as Peyer's patches.

Regarding the gut microbiome, the ability of the immune system to modulate brain development has been recognized [3], and researchers have proposed a critical window for intestinal microbes to influence developmental programming of long-lasting brain function. Interest- 
ingly, the gut microbiota influences blood-brain barrier (BBB) permeability, and studies have suggested that gut microbiota- $\mathrm{BBB}$ communication is initiated during gestation [10] and propagated throughout life [11]. The BBB is critical for proper neuronal function and protects the brain from pathogens. Therefore, dysbiosis leads to a high risk for development of neuropsychiatric disorders, such as white matter injury in preterm infants, ischemic stroke, multiple sclerosis (MS), Alzheimer's disease (AD), and Parkinson's disease (PD) [12].

Several studies involving germ-free animals or animals treated with broad-spectrum antibiotics show that the microbiota can impact CNS physiology and neurochemistry [13]. Germ-free mice that are devoid of associated microflora exhibit neurological deficits in learning, memory, recognition, and emotional behaviors $[14,15]$. Indeed, although based on animal studies or correlation analysis of patient populations, the intestinal flora is implicated in various types of stress, such as anxiety, depression, and irritable bowel syndrome. The intestinal microbiota influences brain chemistry such as neurotransmitters and behavior independently of the autonomic nervous system, gastrointestinal-specific neurotransmitters, or inflammation. The GBA may contribute to psychiatric disorders in patients with bowel disorders [16].

Increasing evidence suggests that dysbiosis is associated with metabolic diseases, such as hypertension and type 2 diabetes. Both diseases are also risk factors for developing stroke. We also reported a significant association between ischemic stroke and both bacteria count and organic acid concentration that were associated with the levels of metabolic and inflammatory biomarkers [17]. Thus, the findings suggest that gut dysbiosis in patients with ischemic stroke is associated with host metabolism and inflammation. Microbial metabolites have been well documented as activators of immune cells.

As mentioned above, the permeable BBB could serve as a gateway for signal transmission, suggesting a role for immune cells, such as macrophages, $\mathrm{CD} 8^{+} \mathrm{T}$ cells, regulatory $\mathrm{T}$ cells, and other $\mathrm{CD} 4^{+} \mathrm{T}$ helper (Th) cell subsets, in the CNS. Resident immune cells are actively involved in innate and/or adaptive immune responses [18-20]. The GBA is involved in promoting different subsets of $\mathrm{CD} 4^{+} \mathrm{T}$ cells through antigen stimulation and activation of immune signaling pathways. Several microbiomes promote development of Th1 cells through the polysaccharide A-dependent pathway and regulatory $\mathrm{T}$-cell differentiation $[21,22]$. In addition, experimental autoimmune encephalomyelitis, a model used for the pathological study of MS, has many similar pathological conditions as MS, including $\mathrm{CD}^{+} \mathrm{Th}$ cells that play an important role. Although Th1 cells play a pathogenic role in MS, Th2 cells exhibit protective function [23]. Thus, the GBA could be involved in the immune system in the CNS.

Moreover, special emphasis has been placed on the GBA not only in neuroautoimmune disorders but also in ischemic stroke. The GBA is implicated in ischemic brain injury after stroke via the regulation of intestinal $\mathrm{T}$ cells $[24,25]$. In addition, stroke causes specific changes in gut microbiota $[25,26]$. Stroke itself also promotes the translocation and dissemination of bacteria from the host gut microbiota as a mechanism leading to poststroke infection [27]. Recently, gram-negative bacteria-derived LPS has been implicated in the neuropathology of human diseased brains. LPS is a potent inflammatory stimulus for the innate immune response via toll-like receptor 4 activation. Indeed, a higher plasma LPS level is associated with worse shortterm outcomes in patients with acute ischemic stroke [28]. Kurita et al. [29] reported that oral administration of a nonabsorbable antibiotic modulates the gut microbiota and improves stroke outcomes in murine models of type 2 diabetes. These findings suggest that targeting metabolic endotoxemia may be a novel potential therapeutic strategy to improve stroke outcomes.

$\mathrm{PD}$ and $\mathrm{AD}$ are chronic and irreversible neurodegenerative diseases and can be said to be typical diseases of movement disorders and dementia, respectively. The pathogenesis of $\mathrm{AD}$ is associated with a peripheral infectious origin that can cause neuroinflammation in the CNS $[30,31]$. Interestingly, $A \beta$ precursor protein (APP)mutant germ-free mice have decreased cerebral $A \beta$ amyloid pathology compared with mutant APP mice in the control condition. Anti-A $\beta$ effects were blocked by reconstruction of the microbiota of these germ-free APP mice with microbiota from conventional mice [32]. Moreover, long-term and broad-spectrum antibiotic treatment also reduces $A \beta$ deposition and improves the phenotype of mice [33].

Recent studies have implicated peripheral influences in the onset and progression of disease in the brain in PD [34]. Thus, PD should be considered a systemic disorder. In addition, evidence from a study of a PD model in which mice overexpress $a$-synuclein, a major component of Lewy bodies, suggests a role for the GBA in the pathogenesis of the disease [35]. $\alpha$-Synuclein transgenic mice housed in a germ-free environment or treated with antibiotics show suppressed deterioration of PD pathology compared with mice housed in regular conditions, simi- 
lar to APP mice [36]. Moreover, the symptom-free state in these germ-free mice was preserved with either colonization via feces from conventional mice or oral administration of bacterial metabolites. These findings indicate that the GBA may be a new therapeutic target for treating not only $\mathrm{AD}$ but also PD.
This special issue consists of 5 review articles. We focus on several CNS disorders, such as mood disorders, stroke, $\mathrm{AD}$, and $\mathrm{PD}$. We hope that this special issue will stimulate and encourage neurologists and psychiatrists to understand the relationship between the GBA and CNS disorders.

\section{References}

1 Track NS. The gastrointestinal endocrine system. Can Med Assoc J. 1980 Feb;122(3):28792.

2 Jones MP, Dilley JB, Drossman D, Crowell MD. Brain-gut connections in functional GI disorders: anatomic and physiologic relationships. Neurogastroenterol Motil. 2006 Feb; 18(2):91-103.

3 Deverman BE, Patterson PH. Cytokines and CNS development. Neuron. 2009 Oct;64(1): 61-78.

4 Perlman JM. Cognitive and behavioral deficits in premature graduates of intensive care. Clin Perinatol. 2002 Dec;29(4):779-97.

5 Udit S, Gautron L. Molecular anatomy of the gut-brain axis revealed with transgenic technologies: implications in metabolic research. Front Neurosci. 2013 Jul;7:134.

6 Forsythe P, Kunze WA. Voices from within: gut microbes and the CNS. Cell Mol Life Sci. 2013 Jan;70(1):55-69.

7 Bonaz BL, Bernstein CN. Brain-gut interactions in inflammatory bowel disease. Gastroenterology. 2013 Jan;144(1):36-49.

8 Matteoli G, Boeckxstaens GE. The vagal innervation of the gut and immune homeostasis. Gut. 2013 Aug;62(8):1214-22.

9 Parrish WR, Rosas-Ballina M, GallowitschPuerta M, Ochani M, Ochani K, Yang LH, et al. Modulation of TNF release by choline requires alpha7 subunit nicotinic acetylcholine receptor-mediated signaling. Mol Med. 2008 Sep-Oct;14(9-10):567-74.

10 Sherman MP. New concepts of microbial translocation in the neonatal intestine: mechanisms and prevention. Clin Perinatol. 2010 Sep;37(3):565-79.

11 Braniste V, Al-Asmakh M, Kowal C, Anuar F, Abbaspour A, Tóth M, et al. The gut microbiota influences blood-brain barrier permeability in mice. Sci Transl Med. 2014 Nov; 6(263):263ra158. https://doi.org/10.1126/scitranslmed.3009759.

12 Engelhardt B, Liebner S. Novel insights into the development and maintenance of the blood-brain barrier. Cell Tissue Res. 2014 Mar;355(3):687-99.

13 Smith PA. The tantalizing links between gut microbes and the brain. Nature. 2015 Oct; 526(7573):312-4.

14 Gareau MG, Wine E, Rodrigues DM, Cho JH, Whary MT, Philpott DJ, et al. Bacterial infection causes stress-induced memory dysfunction in mice. Gut. 2011 Mar;60(3):307-17.
15 Foster JA, Rinaman L, Cryan JF. Stress \& the gut-brain axis: regulation by the microbiome. Neurobiol Stress. 2017 Mar;7:124-36.

16 Bercik P, Denou E, Collins J, Jackson W, Lu J, Jury J, et al. The intestinal microbiota affect central levels of brain-derived neurotropic factor and behavior in mice. Gastroenterology. 2011 Aug;141(2):599-609.

17 Yamashiro K, Tanaka R, Urabe T, Ueno Y, Yamashiro Y, Nomoto K, et al. Correction: gut dysbiosis is associated with metabolism and systemic inflammation in patients with ischemic stroke. PLoS One. 2017 Apr; 12(4): 0176062.

18 Chitnis T, Weiner HL. CNS inflammation and neurodegeneration. J Clin Invest. 2017 Oct;127(10):3577-87.

19 Gjelstrup MC, Stilund M, Petersen T, Møller HJ, Petersen EL, Christensen T. Subsets of activated monocytes and markers of inflammation in incipient and progressed multiple sclerosis. Immunol Cell Biol. 2018 Feb;96(2): $160-74$.

20 Yin J, Valin KL, Dixon ML, Leavenworth JW. The Role of Microglia and Macrophages in CNS Homeostasis, Autoimmunity, and Cancer. J Immunol Res. 2017;2017:5150678.

21 Mazmanian SK, Liu CH, Tzianabos AO, Kasper DL. An immunomodulatory molecule of symbiotic bacteria directs maturation of the host immune system. Cell. $2005 \mathrm{Jul}$; 122(1):107-18.

22 Atarashi K, Tanoue T, Shima T, Imaoka A, Kuwahara T, Momose Y, et al. Induction of colonic regulatory $\mathrm{T}$ cells by indigenous Clostridium species. Science. 2011 Jan;331(6015): $337-41$.

23 Haase S, Haghikia A, Wilck N, Müller DN, Linker RA. Impacts of microbiome metabolites on immune regulation and autoimmunity. Immunology. 2018 Jun;154(2):230-8.

24 Benakis C, Brea D, Caballero S, Faraco G, Moore J, Murphy M, et al. Commensal microbiota affects ischemic stroke outcome by regulating intestinal $\gamma \delta$ T cells. Nat Med. 2016 May;22(5):516-23.

25 Singh V, Roth S, Llovera G, Sadler R, Garzetti D, Stecher B, et al. Microbiota Dysbiosis Controls the Neuroinflammatory Response after Stroke. J Neurosci. 2016 Jul;36(28):7428-40.
26 Houlden A, Goldrick M, Brough D, Vizi ES, Lénárt $\mathrm{N}$, Martinecz $\mathrm{B}$, et al. Brain injury induces specific changes in the caecal microbiota of mice via altered autonomic activity and mucoprotein production. Brain Behav Immun. 2016 Oct;57:10-20.

27 Stanley D, Mason LJ, Mackin KE, Srikhanta YN, Lyras D, Prakash MD, et al. Translocation and dissemination of commensal bacteria in post-stroke infection. Nat Med. 2016 Nov;22(11):1277-84.

28 Klimiec E, Pera J, Chrzanowska-Wasko J, Golenia A, Slowik A, Dziedzic T. Plasma endotoxin activity rises during ischemic stroke and is associated with worse short-term outcome. J Neuroimmunol. 2016 Aug;297:76-80.

29 Kurita N, Yamashiro K, Kuroki T, Tanaka R, Urabe T, Ueno $\mathrm{Y}$, et al. Metabolic endotoxemia promotes neuroinflammation after focal cerebral ischemia. J Cereb Blood Flow Metab. 2020 Jan;271678X19899577.

30 Wyss-Coray T, Rogers J. Inflammation in Alzheimer disease-a brief review of the basic science and clinical literature. Cold Spring Harb Perspect Med. 2012 Jan;2(1):a006346.

31 Cappellano G, Carecchio M, Fleetwood T, Magistrelli L, Cantello R, Dianzani U, et al. Immunity and inflammation in neurodegenerative diseases. Am J Neurodegener Dis. 2013 Jun;2(2):89-107.

32 Harach T, Marungruang N, Duthilleul N, Cheatham V, Mc Coy KD, Frisoni G, et al. Reduction of Abeta amyloid pathology in APPPS1 transgenic mice in the absence of gut microbiota. Sci Rep. 2017 Feb;7(1):41802.

33 Minter MR, Zhang C, Leone V, Ringus DL, Zhang X, Oyler-Castrillo P, et al. Antibioticinduced perturbations in gut microbial diversity influences neuro-inflammation and amyloidosis in a murine model of Alzheimer's disease. Sci Rep. 2016 Jul;6(1):30028.

34 Cryan JF, Dinan TG. Gut microbiota: microbiota and neuroimmune signalling-Metchnikoff to microglia. Nat Rev Gastroenterol Hepatol. 2015 Sep;12(9):494-6.

35 Sampson TR, Debelius JW, Thron T, Janssen S, Shastri GG, Ilhan ZE, et al. Gut Microbiota Regulate Motor Deficits and Neuroinflammation in a Model of Parkinson's Disease. Cell. 2016 Dec;167(6):1469-1480.e12.

36 Caputi V, Giron MC. Microbiome-Gut-Brain Axis and Toll-Like Receptors in Parkinson's Disease. Int J Mol Sci. 2018 Jun;19(6):E1689. 